\title{
La ville d'Athènes dans les mémoires de voyage d'Evliyâ Çelebi et de Jacob Spon
}

Représentations croisées de l'Ailleurs

The city of Athens in the travel memoirs of Jacob Spon and Evliyâ Çelebi:

intertwined representations of Elsewhere

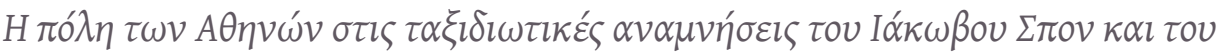

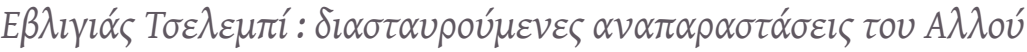

\section{Nicolas Pitsos}

\section{OpenEdition}

Journals

Édition électronique

URL : https://journals.openedition.org/ceb/4013

DOI : 10.4000/ceb.4013

ISSN : 2261-4184

Éditeur

INALCO

Édition imprimée

Pagination : 99-116

ISBN : 978-2-85831-205-4

ISSN : 0290-7402

Référence électronique

Nicolas Pitsos, "La ville d'Athènes dans les mémoires de voyage d'Evliyâ Çelebi et de Jacob Spon », Cahiers balkaniques [En ligne], 41 | 2013, mis en ligne le 20 mai 2013, consulté le 06 juillet 2021. URL: http://journals.openedition.org/ceb/4013 ; DOI : https://doi.org/10.4000/ceb.4013

Ce document a été généré automatiquement le 6 juillet 2021.

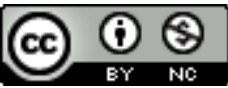

Cahiers balkaniques est mis à disposition selon les termes de la Licence Creative Commons Attribution - Pas d'Utilisation Commerciale 4.0 International. 


\section{La ville d'Athènes dans les mémoires de voyage d'Evliyâ Çelebi et de Jacob Spon}

Représentations croisées de l'Ailleurs

The city of Athens in the travel memoirs of Jacob Spon and Evliyâ Çelebi:

intertwined representations of Elsewhere

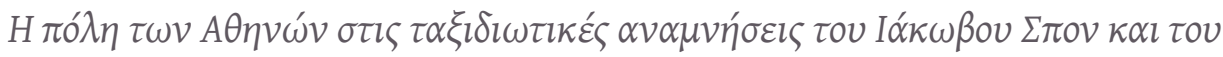

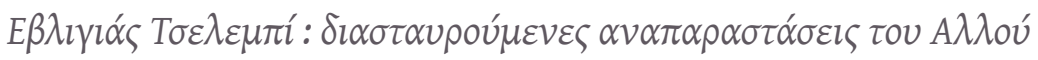

\section{Nicolas Pitsos}

1 Intrigué par la présence quasi simultanée de deux voyageurs dans la ville d'Athènes autour des années 1670, un Français, Jacob Spon et un Ottoman, Evliyâ Çelebi, j’ai voulu retracer dans cet article, leurs souvenirs respectifs. Il s'agit d'esquisser, à travers l'étude des mémoires de ces deux voyageurs qui se rendent à Athènes à quelques années d'intervalle, leurs perceptions de la ville, de son histoire, de sa topographie urbaine (lieux évoqués, monuments commentés), et de son organisation sociopolitique (institutions, relations intercommunautaires, mœurs et coutumes). L'objectif d'une telle analyse est de comprendre en quoi cette juxtaposition d'impressions et d'expressions, est révélatrice d'une représentation différenciée de l'altérité urbaine et humaine. Ma réflexion est principalement nourrie et influencée par l'interrogation centrale de l'histoire culturelle ${ }^{1}$ : comment les individus représentent-ils et se représentent-ils le monde qui les entoure?

2 Les sources documentaires qui m'ont accompagné tout au long de cette exploration, sont les mémoires de Jacob Spon, et le chapitre du livre du voyage d'Evliyâ Çelebi consacré à ses expériences athéniennes que j'ai étudiées à la fois grâce aux traductions grecque de Kostas Biris, historien de la ville d'Athènes ${ }^{2}$, et anglaise de Robert Dankoff et Sooyong Kim dans leur ouvrage intitulé An Ottoman traveller ${ }^{3}$. Je me suis également référé à la version turque du viII ${ }^{\mathrm{e}}$ volume du Seyahatnâme, éditée en 2003, toujours par Robert Dankoff en collaboration avec Seyit Ali Kahraman et Yücel Dağl1 ${ }^{4}$. 


\section{Jacob Spon et Evliyâ Çelebi dans leur contexte historique}

3 Juste avant de braquer nos projecteurs sur la ville d'Athènes à la fin du XVII ${ }^{e}$ siècle, faisons un gros plan sur le contexte historique dans lequel se déplacent ces deux voyageurs. Evliyâ Çelebi effectue son voyage sous le règne de Mehmet IV ${ }^{5}$. Jacob Spon est contemporain de Louis XIV. Les règnes de ces deux souverains se ressemblent à plusieurs égards, tout d'abord par la longévité de leur pouvoir (plus de quarante ans pour chacun), leur début sous forme de régence, puisque c'est la grand-mère de Mehmet IV qui exerce dans un premier temps le pouvoir à sa place, alors que ce rôle est assumé dans le royaume français par Anne d'Autriche. Enfin, tous les deux, sont entourés de personnalités fortes, la famille de Köprülü à Topkapi, le cardinal Mazarin ou le ministre Colbert dans la cour de Versailles. Les parties occidentale et centrale du continent européen sont secouées par les antagonismes religieux de la période précédente (protestants contre catholiques) et se maintiennent dans une agitation guerrière quasi permanente en raison des antagonismes politico-économiques opposant les royaumes anglais, français, hollandais pour le contrôle des routes du commerce maritime. En même temps, l'Empire ottoman traverse une période de relative tranquillité et atteint son apogée territoriale.

4 Evliyâ Çelebi voit le jour dans la capitale de cet empire ${ }^{6}$, la ville d'Istanbul, alors que Jacob Spon naît à Lyon ${ }^{7}$, une ville qui n'est plus à cette époque la capitale du grand commerce et de la banque, mais qui connaît toutefois un nouvel essor grâce aux métiers à tisser. De confession protestante, sa famille est originaire de la ville d'Ulm, dans la région du Wurtemberg, il a la chance de vivre dans une période d'accalmie politico-religieuse à la veille de la révocation de l'édit de Nantes. Reçu docteur de la Faculté de Paris, Jacob Spon va très vite préférer l'archéologie à la médecine. En 1674, il fait la connaissance d'un antiquaire, du nom de Vaillant, qui passait par Lyon pour se rendre en Italie, où il avait été chargé par Louis XIV d'aller faire des recherches sur les antiquités et particulièrement sur les médailles. Après avoir traversé l'Italie où il rencontre Wehler, un collectionneur anglais, et suite à leur passage par la capitale ottomane, ils entrent à Athènes le 6 février $1676^{\circ}$. Ils se dirigent directement au pied de l'Acropole vers la maison de Monsieur Giraud consul d'Angleterre lyonnais de naissance, chez lequel ils logent durant leur séjour?

\section{Objectif du voyage chez Jacob Spon et Evliyâ Çelebi}

5 D'après Robert Dankoff ${ }^{10}$, la motivation principale de Çelebi est de décrire la géographie humaine (l'histoire, les coutumes, le folklore) et la topographie des lieux qu'il visite, tout en nous livrant un essai autobiographique.

6 Jacob Spon voyage quant à lui, en tant que médecin et archéologue, je dirais comme agent d'un antagonisme culturel développé entre plusieurs royaumes européens, notamment anglais, français et hollandais, qui se lancent dans une course à l'enrichissement de leurs collections royales par des antiquités gréco-romaines, afin d'asseoir leur pouvoir et de signifier leur rayonnement. Son regard utilitariste visant à vérifier sur place des connaissances déjà acquises sur une Antiquité, à la fois de socle de 
légitimation au pouvoir royal, et clef de voûte dans la glorification de sa majesté, s'oppose à une démarche de curiosité intellectuelle et de glorification du voyage pour le voyage, propre au regard de Çelebi.

\section{Sur les origines et l'histoire de la ville d'Athènes}

7 Malgré leurs objectifs divergents, les deux voyageurs commencent leur récit par un rappel des origines de la ville. Le médecin lyonnais, affirme que "l'antiquité trop crédule, qui attribuait tout ce qu'elle voyait d'illustre aux soins de quelque Divinité, s'imagina que Minerve elle-même avait pris le soin de bâtir Athènes (...) la plupart néanmoins demeurent d'accord, que ce fut Cecrops premier roi des Athéniens qui en jeta les fondements ${ }^{11}$ ». De son côté, Evliyâ, prenant comme témoins les chroniqueurs chrétiens de la communauté messianique et les chroniqueurs coptes, évoque comme fondateur de la ville le prophète Salomon et il raconte à cette occasion l'histoire du voyage merveilleux à travers la ville de Jérusalem et l'île de Crète, de la Mère Belkis ${ }^{12}$, c'est-à-dire de la reine de Saba, honorée dans le Coran. Selon l'érudit grec Kostas Biris ${ }^{13}$, ce qui apparaît comme une information contradictoire ou erronée sur l'histoire de la ville ou d'un monument, n'est pas forcément révélateur d'informations ou de connaissances lacunaires. Cela pourrait également nous renseigner sur les croyances au sujet de l'évolution historique de la ville entretenues par ses habitants à cette époque que Çelebi avait recueillies en les interrogeant à ce sujet. On pourrait par exemple y voir l'empreinte, l'emprise d'une longue tradition historiographique d'inspiration et orientation chrétienne qui aurait réinterprété les événements historiques à sa guise.

8 En ce qui concerne l'évolution historique de la ville d'Athènes, Jacob Spon puise largement pour l'antiquité à la source d'Hérodote, de Pausanias, et des chroniqueurs byzantins, égrenant les noms de rois légendaires et des dirigeants historiques. Sa liste commence avec Cécrops fondateur mythique et s'achève avec Mehmet II, s'interrompant à Justinien pour ne reprendre qu'à Boniface II, marquis de Montferrat qui assura une présence franque dans l'Attique et la Béotie, au tout début du XIII siècle. La période byzantine post-justinienne est complètement gommée: "Justinien lui voulut du bien, mais depuis ce temps-là pendant sept cents ans, on n'entend plus parler d'elle, soit à cause de l'Histoire qui est courte et obscure dans ces siècles-là, ou que la fortune lui eût accordé ce long repos ${ }^{14} »$.

9 Evliyâ, dans sa généalogie historique de la ville, accorde au roi Philippe (Melik Feylekos), une place particulièrement importante. Après lui, la ville d'Athènes serait passée d'un roi à l'autre, de la domination espagnole à celle des Francs Vénitiens jusqu'à l'année de la conquête ottomane sous le règne du sultan Mehmet le conquérant ${ }^{15}$. L'extrait suivant est révélateur de la place importante dans l'imaginaire des citoyens athéniens du $\mathrm{XVII}^{\mathrm{e}}$ siècle du personnage de Philippe. Evliyâ Çelebi relate la croyance selon laquelle le tombeau à l'intérieur de la Tour des Vents appartiendrait au roi macédonien. Cet extrait est aussi très intéressant à un autre égard, car il met en évidence la distinction opérée par les Ottomans contemporains de Çelebi entre les Yunan (Grecs anciens) et les Rums, sujets chrétiens du sultan composant un millet du même nom ${ }^{16}$.

10 Cette distinction n'est pas pratiquée par Jacob Spon, qui raisonne au sujet des habitants de la ville, en termes de Grecs et de Turcs, alors qu'au contraire Evliyâ Çelebi emploie les termes de musulmans et infidèles (Keferler) ou Rums ${ }^{17}$. Ce constat n'est pas propre aux citadins athéniens mais je voulais le commenter car cette appellation 
différenciée est révélatrice de toute une perception et définition de l'Autre et nous montre à quel point un amalgame entre Grec et chrétien et entre Turc et musulman est déjà présent chez les voyageurs, observateurs venant de l'Europe de l'Ouest au $\mathrm{xVII}^{\mathrm{e}}$ siècle. Démonstration éloquente de ce phénomène, les estimations démographiques des deux voyageurs. Selon Evliyâ Çelebi, le nombre des infidèles enregistrés pour verser le haraç serait de 4000 . En revanche, il commente le fait que « les Musulmans dans cette ville sont méprisés, sans réputation, parce que les Infidèles sont des grands marchands ayant des associés en Europe occidentale $\aleph^{18}$. Dans l'univers mental de Jacob Spon, Athènes peut contenir huit à neuf mille habitants, dont les trois quarts sont Grecs, et les autres Turcs. Il évoque également les Francs, qui sont en si petit nombre, qu'il n'y a pas de quoi en faire une Académie. «Il n'y avait lorsque nous y étions, que les deux Consuls, qui ne se voient qu'en des visites sérieuses; qu'un Père Capucin, un Arquebusier Français et quelques valets $»^{19}$.

\section{Sur l'organisation institutionnelle et administrative de la ville}

11 Si le voyageur français pratique aisément ce que j'appelle l'hétéro-définition de l'Autre, en ne prenant en compte ni la nomenclature officielle en vigueur dans une société ottomane de l'époque, ni la façon dont les citoyens se définissaient eux-mêmes, il n'hésite pas pour autant à recourir aux notions d'identification dominante, c'est-àdire à des notions d'appartenance confessionnelle, quand il affirme que :

Le Cady est le juge de tous les différends, tant des chrétiens, que des Musulmans. Il est vrai que les premiers pour éviter le plus qu'ils peuvent ce tribunal sévère, tâchent de régler leurs différends par les Épitropes ou Vechiardos qui sont huit de leurs anciens qu'on change tous les six mois et l'on en prend un de chacune des huit paroisses ${ }^{20}$.

Tableau 1 : Division de la ville d'Athènes en quartiers

\begin{tabular}{|c|c|}
\hline Nom du quartier & Indices topographiques de Jacob Spon \\
\hline Placa & $\begin{array}{l}\text { "au Levant vers le Fanari ... l'église d'Agia Kira et la maison du consul } \\
\text { Giraud» }\end{array}$ \\
\hline Sotiras tou Cotaki & « le quartier qui regarde l'église Lycodemou» \\
\hline Monocaluftis & $\begin{array}{l}\text { au centre de la ville vers la mosquée neuve tiz Beynas, du nom d'une veuve } \\
\text { qui la fît bâtir " }\end{array}$ \\
\hline Roumbi & $\begin{array}{l}\text { "aux environs de l'église Panagia Camoucaria et vers le quartier où se fait } \\
\text { la chaux» }\end{array}$ \\
\hline Boreas Platoma & « au Nord de la ville où est l'église de Chrysospiliotisa » \\
\hline Psiri Platoma & $\begin{array}{l}\text { "au Couchant de cette église et aux environs de la Colonne appelée Agios } \\
\text { Ioannis" }\end{array}$ \\
\hline Gerlada & « au bas du château et de l'église appelée Agio Nicolo » \\
\hline $\begin{array}{l}\text { Agioi Colymboi ou } \\
\text { Olympoi }\end{array}$ & « du côté d'Éleusis et du Temple de Thésée » \\
\hline
\end{tabular}


12 Ces hauts dignitaires de la communauté des Rums athéniens ne sont pas cités par Evliyâ Çelebi, selon qui, la communauté d'infidèles n'a qu'un seul magistrat, le métropolite ${ }^{21}$. Par contre, Evliyâ Çelebi nous livre une liste détaillée de hauts dignitaires ottomans musulmans de la ville. En lisant ses souvenirs on apprend aussi qu'Athènes faisait, à l'époque, partie du vilayet de Roumeli sous la protection de Kapudan-pacha et elle était vakuf de la ville de Mecque et de Médine ${ }^{22}$.

Tableau 2 : Liste des hauts dignitaires de la ville d'Athènes cités par les deux voyageurs

\begin{tabular}{|l|l|}
\hline Evliyâ Çelebi & Jacob Spon \\
\hline vâlı̂ & Voïvode \\
\hline yeniçeri serdârısı & Sardar \\
\hline sipâh kethudâyerisi & Spahilar-Aga \\
\hline kal'anın dizdâr ağası & Disdar ou Aga du Château \\
\hline kadi & Cady \\
\hline - & Epitropes ou Vechiardos \\
\hline mufti & \\
\hline merdüm-hisârısı ve muhtesib ă̆ası & \\
\hline bâcdâr ağası & \\
\hline harâc ă̆ası & \\
\hline emîn ağası & \\
\hline şehir kethudâsı ve mi'mâr ağası & \\
\hline şehir subaşısı & \\
\hline patirgâhh & \\
\hline
\end{tabular}

\section{Sur l'espace profane}

13 Esquissant par la suite l'espace profane de cette ville, le voyageur ottoman relate la nature des habitations privées, aux toits à tuiles ${ }^{23}$, informe ses lecteurs sur l'état de la voirie, - des rues qui ne sont pas pavées ${ }^{-24}$. Il insiste également sur la présence des nombreux puits ${ }^{25}$, et il commente l'état délabré des fontaines ${ }^{26}$.

14 Néanmoins, le critère suprême pour l'évaluation de la prospérité d'une ville, est chez Evliyâ Çelebi, la qualité de ses hammams ainsi que l'existence des bedestens ${ }^{27}$. Pour la ville d'Athènes, il nous indique les noms des trois hammams à l'ambiance agréable, 
mais il souligne l'absence de bedesten. Malgré cela, il constate que le marché athénien est suffisamment approvisionné en matières précieuses et marchandises de valeur ${ }^{28}$.

On retrouve la même conclusion chez Jacob Spon qui affirme que les denrées pour l'usage ordinaire des habitants sont en abondance à Athènes. Parmi les produits d'exportation, il distingue des savons faits avec la cendre de lentisque, des vins bons mais d'un goût un peu bizarre, car les Grecs enduisent les tonneaux pour empêcher les vins de se gâter. Enfin, pour ce qui est des olives, « elles y sont excellentes, mais il y en a particulièrement une espèce qu'on aurait de la peine à trouver ailleurs et dont on ne peut point faire d'huile (...). On les appelle Colymbades, et elles sont si estimées que le Grand Seigneur les fait presque toutes retenir pour sa bouche ${ }^{29}$ ».

16 En dehors de la description du bazar et de ses activités commerciales, le voyageur lyonnais se promène aussi au milieu des maisons de plaisance et des beaux jardins du quartier de Sepollia où il se croit être à l'endroit de l'Académie, en raison, comme il l'avoue lui-même, de la beauté du lieu et de la bonté du terroir qui porte des citronniers et des orangers ${ }^{30}$.

Le marché-bazar d'Athènes au début du XIX siècle d'après une aquarelle d'Edward Dodwell qui visita cette ville ottomane en 1805

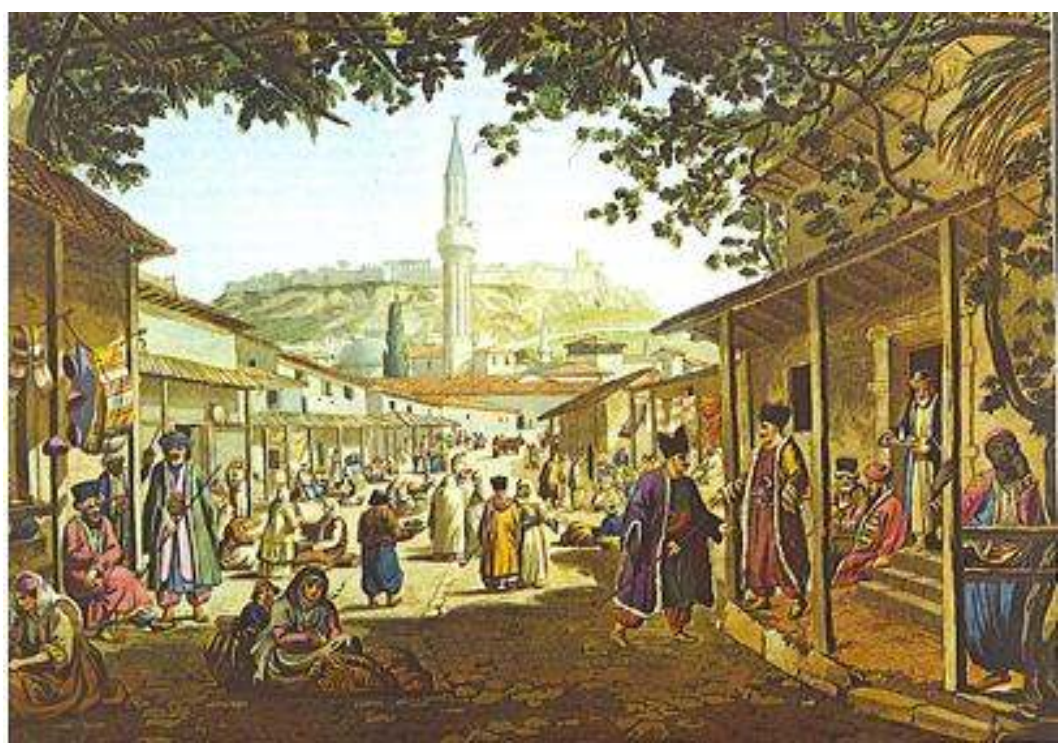

SOURCE : EDWARD DODWELL, VIEWS IN GREECE WITH THIRTY COLOURED PLATES, LONDON, 1821

\section{Sur l'espace sacré}

17 Les pérégrinations dans l'espace profane mises à part, les deux voyageurs consacrent une bonne partie de leurs narrations à l'espace sacré. Vu qu'ils se rendent à Athènes avant le siège par l'amiral vénitien Morosini en 1687 qui a abouti à une destruction partielle du Parthénon, ce monument attire leur admiration et monopolise dans un premier temps leur attention.

Jacob Spon se hâte d'aller voir la grande Mosquée, qui était autrefois le Temple de Minerve. Evliyâ en fait autant de son côté. Leurs descriptions de la citadelle de l'Acropole sont des sources précieuses pour la reconstitution virtuelle de cet ensemble monumental. Si les détails architecturaux sont quasi identiques chez les deux 
observateurs, leurs sensibilités culturelles les amènent à des appréciations différenciées de son esthétique. J'ai relevé deux éléments qui illustrent bien, me semble-t-il, ces divergences.

19 Tout d'abord la question de lumière. Jacob Spon, parle d'obscurité et il observe que toute la lumière qu'elle recevait cette mosquée :

...vient du fond que les Chrétiens avaient ouvert en faisant le chœur; qu'ainsi du temps des Payens ce Temple n'avait aucun jour que celui qu'il pouvait recevoir par la Porte... ils s'imaginaient sans doute que l'obscurité avait quelque chose de plus majestueux et qui imprimait plus de respect à ceux qui entraient dans les Temples. C'est apparemment de là qu'est venu l'usage des lampes dans les lieux sacrés ${ }^{31}$.

La ville d'Athènes en 1675, avec les minarets des mosquées de la ville et en gros plan, le Parthénon. Jacob Spon

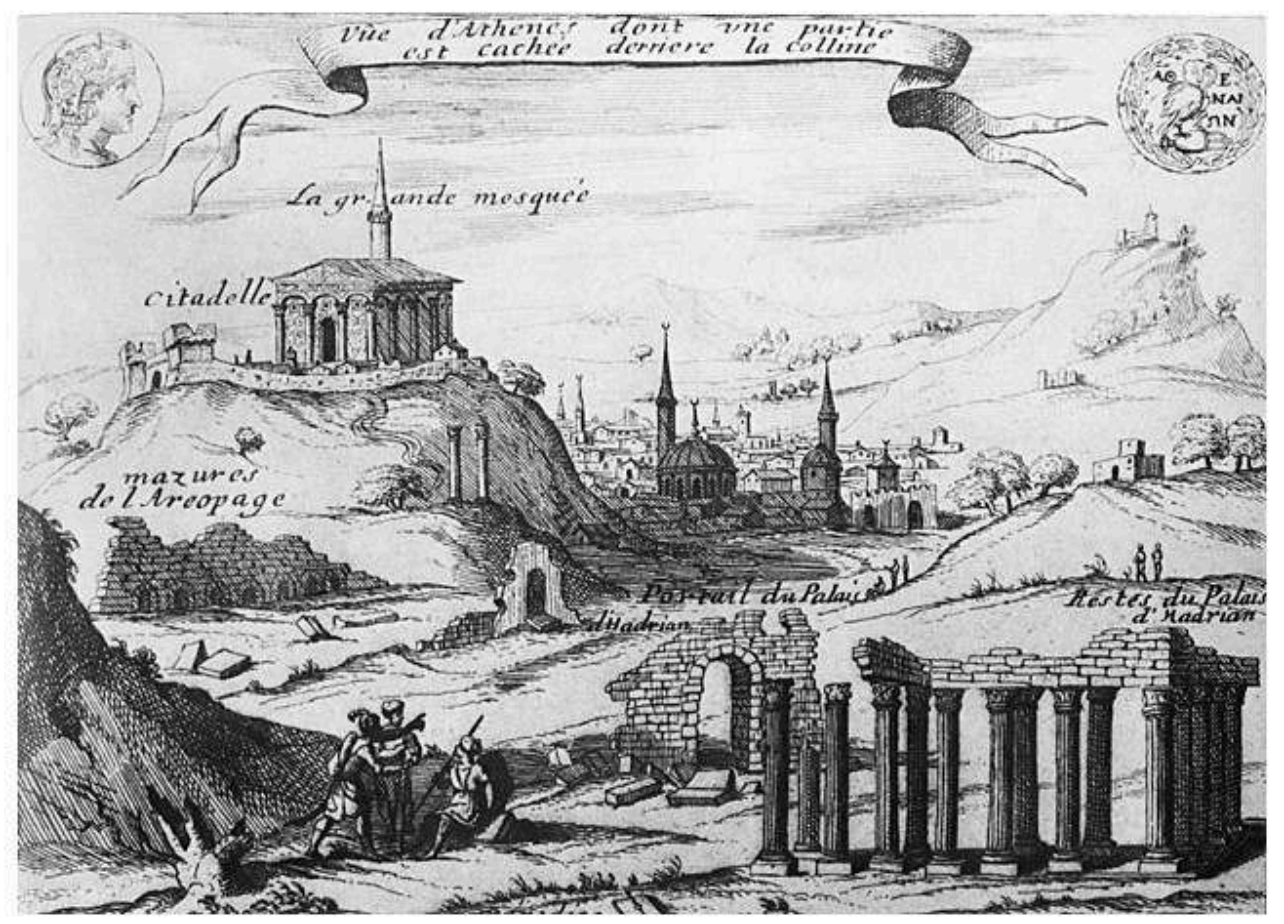

Voyage d'Italie, de Dalmatie, de Grèce et du Levant, fait aux années 1675 et 1676, Lyon, 1678, vol. ॥

De son côté, Evliyâ Çelebi, juge ce lieu de culte suffisamment éclairé. Il est surtout stupéfait par les sculptures à l'extérieur du temple. Faisant probablement allusion aux scènes mythologiques représentées sur les métopes, il y voit une succession de créatures paradisiaques ou infernales selon où il tourne son regard ${ }^{32}$.

21 Quant au voyageur français, il se montre très sévère à l'égard du traitement réservé aux fresques au moment de la transformation en mosquée du lieu qui avait servi également au culte chrétien pendant la période byzantine. On n'y voit plus désormais qu'une représentation de la Sainte Vierge, à la voûte, souligne-t-il, «qu'on a laissée parce qu'on dit qu'un Turc y ayant un jour tiré un coup de mousquet, la main de ce profane sécha aussitôt $t^{33}$ ». Très rationnel et critique à l'égard des légendes, il se laisse emporter à cette occasion...

22 Son incompréhension devant des sensibilités artistiques et spirituelles autres que celles de la Renaissance ou du Baroque, auxquelles il est habitué, s'exprime également lors de son jugement dépréciatif à l'égard des représentations picturales d'un lieu de 
culte chrétien sur la colline de Philoppape : « les Grecs ont changé ce temple en église appelée Panagia, et l'ont rempli de peintures à fresque de leur manière qui est très misérable, car ils font tous les nez et les doigts fort longs comme des fuseaux et le reste aussi mal proportionné $»^{34}$. en une seule phrase ${ }^{38}$. Par contre, c'est grâce à lui qu'on connaît un peu mieux la géographie de l'espace sacré musulman athénien à la fin du XvII siècle. Il évoque la présence des trois quartiers musulmans, avec trois mosquées de vendredi, quatre si l'on compte celle de la citadelle. Il y aurait en plus, sept mesdjid de quartier, un medrese, trois mekteb, et deux tekke ${ }^{39}$. L'un de ces deux tekke, construit d'après le texte d'une inscription qu'il nous transmet en 1023/1614, serait situé aux pieds de la citadelle, et il appartiendrait selon Evliyâ à l'ordre sufi des Halveti ${ }^{40}$. Enfin, il nous indique aussi l'usage du temple d'Olympeion, censé construit pour la mère Belkis par le roi Salomon, comme mosquée en plein air, où les musulmans communauté de la ville se réunissaient pour célébrer les fêtes religieuses ${ }^{41}$.

\section{Sur l'aspect socioculturel de la ville, les relations intercommunautaires, les mœurs et coutumes de ses habitants}

27 À propos de l'absence de communauté israélite à cette époque dans la ville d'Athènes, Jacob Spon déclare que "les juifs n'y sont pas soufferts ${ }^{42}$ ». Ce constat est confirmé par Evliyâ Çelebi qui évoque lui aussi le phénomène de l'antisémitisme chrétien ${ }^{43}$. À côté de cette animosité envers les sujets ottomans de confession judaïque, Jacob Spon, relate 
également l'aversion des chrétiens orthodoxes pour les Latins ${ }^{44}:$ «il serait très rare de voir que quelque Grec se vint confesser chez eux ».

En dehors des relations intercommunautaires, un autre élément du tableau socioculturel qui attire l'attention de nos deux voyageurs, est la moralité de sa vie publique. Selon le médecin lyonnais :

Athènes n'est pas une ville de débauches, on y est sage par habitude, ou par nécessité et l'on n'y sait ce que c'est le jeu. Car quels joueurs y aurait-il à Athènes ? Les Turcs ni les Grecs n'entendent pas nos jeux, et ne se soucient pas de les apprendre ${ }^{45}$.

Ce n'est pas l'avis d'Evliyâ Çelebi qui nous raconte une version plus palpitante quant à la façon de se divertir des femmes athéniennes, qui au tomber du soleil, se munissent des lanternes et festoient dans les hammams ou les maisons particulières jusqu'à l'aube ${ }^{46}$.

Tous les deux relatent les signes de distinction sociale liés aux codes vestimentaires, ou plutôt, mettent en évidence la façon dont les couleurs et la nature des vêtements participent de la différenciation sociale au sein d'une société ottomane. L'habit des Grecs d'Athènes est fort différent de celui des Turcs nous informe Jacob Spon, « car ils ne portent que des vestes étroites, de couleur noire ou obscure, avec des bottines noires » joignant la jambe, au lieu que les Turcs ne portent des bottes qu'à la campagne, ou dans le mauvais temps, et ces bottes-là sont jaunes, avec de larges vestes de couleur, et le turban sur la tête $»^{47}$. Quant aux reaya infidèles, Evliyâ Çelebi observe qu'ils portent sur leur tête le manlifke ${ }^{48}$ qui ressemble à ce que les Francs portent eux aussi ${ }^{49}$.

Enfin au sujet des pratiques linguistiques des Ottomans athéniens, les deux voyageurs remarquent qu'à la fois le grec et le turc servent de langues de communication aux membres des deux communautés confessionnelles principales de la ville. Jacob Spon est également sensible aux analogies entre la version moderne du grec et le grec ancien, en remarquant que dans le dialecte athénien de son époque il y a toujours des réminiscences de l'antiquité, sans que cela veuille dire que les Athéniens du XVII siècle comprennent le grec ancien : « car lorsque nous étions à Athènes il n'y avait que trois Grecs qui y fussent savants, l'Archevêque, l'Abbé de Cyriani, et le sieur Georgio Médecin Candiote $^{50}$ ». De son côté, Evliyâ Çelebi nous fournit un petit lexique gréco-turc, devançant en cela les guides Bædeker du XIX ${ }^{\mathrm{e}}$ siècle et autres guides touristiques de nos jours.

Tableau 3. Des mots et expressions du grec athénien du XVII siècle cités parEvliyâ Çelebi51

\begin{tabular}{|l|l|}
\hline Ipsomi & ekmekdir \\
\hline Nero & su \\
\hline Tiri & peynir \\
\hline Kıryaş & et \\
\hline ankurya & hıyar \\
\hline Pepon & kavun \\
\hline
\end{tabular}




\begin{tabular}{|c|c|}
\hline koromidya & soğan \\
\hline Kiri & mûm \\
\hline Angeli & melek \\
\hline Isvet Nikola & Sarı Saltık \\
\hline naldırfim & Kız karındaş \\
\hline Ipsarya & ballk \\
\hline Pu payisto & Nerede idin \\
\hline Esi supa ela kaç kato & Bire sus gel otur \\
\hline Sika pano matyam & Kalk yukaru cânım \\
\hline Dozmga fora nase zoko ena folori & Bir kerre ver bana sana bir altun vereyim \\
\hline Kali mera kiritsi & Sabâhu'l-hayr çelebi \\
\hline Kalisi mera mastori & Yâ sabâhu'l-hayr usta \\
\hline Keratsa & kadıncık \\
\hline Kiritsi & çelebi \\
\hline Pedaki & Oğlan \\
\hline Magir & bıçak \\
\hline Kasro & Kal'a \\
\hline Pirgaz & hisâr \\
\hline Ela mesa & Gel içeri \\
\hline Lazika & papas \\
\hline mitropolid & kadl \\
\hline patirgâh & Hâkimdir, ya'nî ulu kral pâyesidir \\
\hline
\end{tabular}

\section{Conclusion}

32 Jacob Spon quitte Athènes, le 15 mars 1676 sans avoir oublié auparavant de commenter les traditions pratiques médicales locales ${ }^{52}$. Evliyâ Çelebi, prononce quant à lui, ce qu'il nous présente comme étant les derniers mots de Platon : « 0 , Athènes, mon jardin de paradis $»^{53}$. 
Malgré leur nature anecdotique, l'étude de ces documents est aussi susceptible de nous renseigner sur la perception différenciée de l'Ailleurs et, ce faisant, de mettre en relief les sensibilités et mentalités différentes à l'aune desquelles cet Ailleurs est abordé, signifié et relaté. De surcroît, ces récits faute de documents officiels sur la ville d'Athènes de cette période, représentent des sources précieuses pour la reconstitution du paysage urbain et social pendant la période ottomane ${ }^{54}$. Leur caractère complémentaire, car en fonction de ses bagages culturels chaque voyageur ne retient pas et ne diffuse pas forcément les mêmes informations sur les réalités sensorielles et institutionnelles de la ville, révèle l'intérêt d'une approche comparatiste. Rien bien évidemment ne peut remplacer un déplacement virtuel. Si on n'a pas voyagé à Athènes soi-même et si on ne l'a pas vu de ses propres yeux, on ne peut pas comprendre ce à quoi elle ressemblait jadis ${ }^{55}$, nous dit Evliyâ Çelebi. La description ne peut pas rendre justice à ses merveilles. Et il cite le vers suivant : «Comment écouter peut-il se mesurer à voir ? $»^{56}$ avant de prononcer son verdict final : «Quiconque n'a pas vu cette ville, ne pourra pas se considérer comme voyageur du monde $»^{57}$.

\section{BIBLIOGRAPHIE}

Bacqué-Grammont, Jean-Louis, (2007) «Salomon et la reine de Saba dans la mémoire littéraire ottomane : quelques exemples » p. 151-208, dans Bacqué-Grammont Jean-Louis, Jean-Marie Durand (éd.), L'image de Salomon, sources et postérités, Paris, Louvain : Peeters.

Biçakçi, Ismail, (2003), Yunanistan'da Türk mimari eserleri [Les œuvres architecturales turques en Grèce], Istanbul : İSAR, 2003.

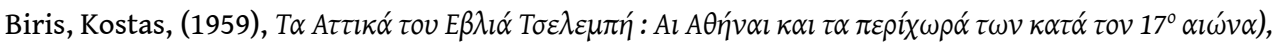
[Les chapitres sur l'Attique d'Evliyâ Çelebi : la ville d'Athènes et ses faubourgs au XVII siècle], Athènes.

Çam, Nusret (2000) Yunanistan'daki Türk eserleri [Les monuments turcs en Grèce], Ankara, TTK, XXI (8).

Çelebi, Evliyâ, (2003) Seyahatnamesi, Istanbul: Topkapi Sarayi Kütüphanesi Bagdat 308 Numaraleu Yazmaneun Transkripsiyonu-Dizini.

Dankoff, Robert, Sooyong Kim, (2010), An ottoman traveller: selections from the Book of Travels of Evliyâ Çelebi, London: Eland.

Dankoff, Robert, (2004), An Ottoman mentality: the world of Evliyâ Çelebi, Leiden: Brill.

Gangloff, Sylvie, (2005) La perception de l'héritage ottoman dans les Balkans (actes des Journées d'études sur l'héritage ottoman dans les Balkans, Istanbul, 16-17 juin 2000), Paris : L'Harmattan.

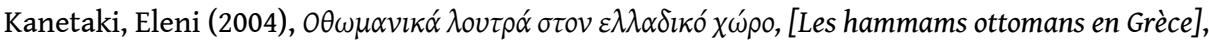
Athènes : TEE.

Kiel, Machiel, (2005), « Un héritage non désiré : le patrimoine architectural islamique ottoman dans l'Europe du Sud-Est, 1370-1912 », Études Balkaniques, 2005, 12, p. 15-82.

Lory, Bernard, (1985) Le sort de l'héritage ottoman en Bulgarie : l'exemple des villes bulgares, Istanbul : Éditions Isis. 
Mackenzie, Molly, (1992), Turkish Athens: the forgotten centuries: 1456-1832, Reading: Ithaca Press.

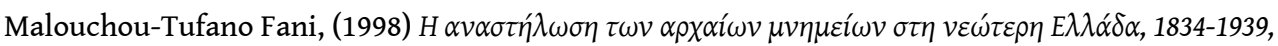
[La restauration de monuments de l'antiquité dans la Grèce contemporaine, 1834-1939]. Athènes : Société Archéologique d'Athènes.

Mollière, Antoine, (1905), Une famille médicale lyonnaise au XVIII siècle : Charles et Jacob Spon, Lyon.

Ory, Pascal, (2004), L'histoire culturelle, Paris : PUF.

Rioux Jean-Pierre, Sirinelli, Jean-François, (1997), Pour une histoire culturelle, Paris : Éditions du Seuil.

Roland, Étienne, Mossière, Jean-Claude (1993) «Jacob Spon : un humaniste lyonnais du XVII ${ }^{\mathrm{e}}$ siècle » exposition, Lyon, 20 octobre-8 décembre 1993, organisée par la Gypsothèque de l'Université Lumière Lyon 2.

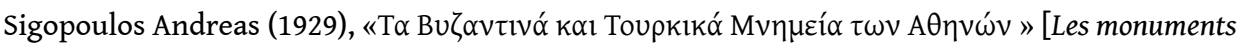

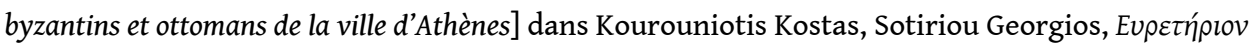

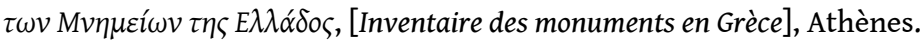

Spon, Jacob, (1678), Voyage d'Italie, de Dalmatie, de Grèce et du Levant, fait aux années 1675 et 1676, Lyon : A. Cellier fils.

Travlos Ioannis, (1972), Athènes au fil des temps : atlas historique d'urbanisme et d'architecture, Paris.

Xarkiolakis Nikolaos (dir.), A

[Restauration et rénovation de bâtiments historiques dans le département d'Attiki], vol. 3, Athènes, 2006.

\section{NOTES}

1. Sur les approches et méthodes épistémologiques de l'histoire culturelle voir, Jean-Pierre Rioux, Jean-François Sirinelli, Pour une histoire culturelle, Paris, éd. du Seuil, 1997 et Pascal Ory, L'histoire culturelle, Paris, PUF, 2004.

2. Voir Kostas Biris, Les chapitres sur l'Attique d'Evliyâ Çelebi : la ville d'Athènes et ses faubourgs au

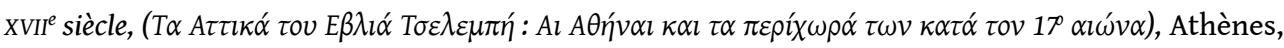
1959.

3. Voir Robert Dankoff, Sooyong Kim, An ottoman traveller: selections from the Book of Travels of Evliyâ Çelebi, London, Eland, 2010.

4. Evliyâ Çelebi, Seyahatnamesi, VIII Kitap, Topkapi Sarayi Kütüphanesi Bagdat 308 Numaraleu Yazmaneun Transkripsiyonu-Dizini, Istanbul, 2003.

5. Son règne dure presque quarante ans (1648-1687). Il est surnommé Avcl (le chasseur).

6. Evliyâ Çelebi est né vers 1611 et décède en 1684. Du côté de sa mère il est parent avec Melek Ahmed Pacha qui devient grand-vizir en 1650-51. Evliyâ Çelebi a l'occasion de voyager à travers les différentes régions de l'Empire ottoman dans sa qualité de nedîm, c'est-à-dire, compagnon familier de gouverneurs et vizirs qu'il suit dans leurs diverses affectations et missions.

7. Antoine Mollière, Une famille médicale lyonnaise au XVIII siècle : Charles et Jacob Spon, Lyon, 1905 et Étienne Roland, Jean-Claude Mossière, "Jacob Spon: un humaniste lyonnais du XVII ${ }^{\mathrm{e}}$ siècle " exposition, 20 octobre-8 décembre 1993, Gypsothèque de l'Université Lyon 2.

8. Roland Étienne, Jean-Claude Mossière, op. cit., p. 216.

9. Ibidem.

10. Robert Dankoff, An Ottoman mentality: the world of Evliyâ Çelebi, Leiden, Brill, 2004, p. 10. 
11. Jacob Spon, Voyage d'Italie, de Dalmatie, de Grèce et du Levant, fait aux années 1675 et 1676, Lyon, A. Cellier fils, 1678, vol. II, p. 105.

12. "Be-kavl-1 cemî-i müverrihân-ı nasârâ-yı millet-i Mesîhiyye ve müverrihîn-i millet-i Kıptî Idrîsiyye bu Atina şehrinin ibtidâ bânîsi Hazret-i Süleymân aleyhi's-selâm'dır kim kaçan Belkîs Ana'yı Yemen diyârında Sebâ pâdişahının duhter-i pâkîze-ahteriyken perîlere Belkîs Ana'yı bir gece came-hâbıyla getirdüp menkûhalığa kabûl edüp Belkîs Ana kesb-i hevâ içün cihânı seyr (ü) temâşâ etmek murâd edindikde Hazret-i Süleymân rûzgâra emr edüp Kuds-i şerîf'den bârgâhıyla Hazret-i Süleymân ma'a Belkîs Ana ber-hevâ tayerân ederek ibtidâ cezîre-i Girid'de kûh-1 Isfakiyye'nin tâ zirve'i a'lâsında makarr edüp Belkîs Ana'ya anda bir kasr-1 âlî bünyâd eder" dans Evliyâ Çelebi, Seyahatnamesi, VIII Kitap, op. cit., p.113. Pour une traduction commentée de ce passage, voir Jean-Louis Bacqué-Grammont, "Salomon et la reine de Saba dans la mémoire littéraire ottomane : quelques exemples », p. 151-208, dans Jean-Louis Bacqué-Grammont, JeanMarie Durand (ed.), L'image de Salomon, sources et postérités, Paris, Louvain, Peeters, 2007.

13. Voir Kostas Biris, op. cit., p. 12.

14. Jacob Spon, op. cit., p. 119.

15. “andan sene (...) târîhinde âl-i Osmâniyân'dan bizzât Ebü'l-feth Sultân Mehemmed Hân fethidir" dans Evliyâ Çelebi, Seyahatnamesi, viı Kitap, op. cit., p. 114.

16. "Ammâ bu çadır şeklindeki kubbenin içinde bir kabir var, "Feylekos-ı Yûnânî bunda medfûndur' derler. Cümle Rûm kefereleri I’tibâr edüp bed-nâm günlerinde ziyâret ederler.” dans Evliyâ Çelebi, Seyahatnamesi, viII Kitap, op. cit., p. 118-119.

17. Sur la distinction entre les termes Yunan et Rum dans l'œuvre d'Evliyâ Çelebi, voir Tansu Açık, "Evliyâ çelebi'de Yunan-Roma dünyası", p. 23-33, dans Nuran Tezcan, Çağının Sıradışı Yazarı Evliyâ Çelebi, 2009.

18. "ve cümle küffârı hîn-i tahrîrde dörd bin harâc tahrîr olmuş ammâ on bin küffârdan mütecâviz kefere-i fecereler vardır. (...). Müselmânları aslâ sevilmeyüp müslimînlerin bu şehir(d)e vak'u vakâr I'tibârları yokdur, zîrâ kefereleri gâyet ankâ bâzergânlardır. Tâ dip Frengistân'da ortalkarı vardır." dans Evliyâ Çelebi, Seyahatnamesi, vIII Kitap, op. cit., p. 117-118.

19. Jacob Spon, op. cit., p. 235.

20. Jacob Spon, op. cit., p. 237.

21. “(..) urûmlar üzre bir patirgâh keferesi var, gayri hâkimleri yokdur.” dans Evliyâ Çelebi, Seyahatnamesi, viII Kitap, op. cit., p. 118.

22. "Hâlâ Rûmeli eyâletinde kapudan paşa hükmünde (...) sancağı hâkinde Mekke ve Medîne vakfi olup (...)." dans Evliyâ Çelebi, Seyahatnamesi, viII Kitap, op. cit., p. 114.

23. "cümle yedi bin added kiremit örtülü" dans Evliyâ Çelebi, Seyahatnamesi, VIII Kitap, op. cit., p. 117.

24. “...ve cümle sokakları pâk kumsal zemîndir kim aslâ çamur olmadığından bu şehirde aslâ kaldırım yokdur." dans Evliyâ Çelebi, Seyahatnamesi, viı Kitap, op. cit., p. 117.

25. “(...) cümle dörd bin added evlerde âb-ı hayât su kuyuları vardır." dans Evliyâ Çelebi, Seyahatnamesi, viII Kitap, op. cit., p. 118.

26. "Kefere zamânında bu şehir içre cümle yüz on sekiz yerde çeşme-i aynü'l-hayâtlar var imiş kim her hânedânda birer âb-1 nâblar cereyân edermiş. şimdiki hâlde yolları harâb olup çeşme yerleri râygândır." dans Evliyâ Çelebi, Seyahatnamesi, VIII Kitap, op. cit., p. 118.

27. Voir Robert Dankoff, An ottoman mentality, op.cit., p. 50.

28. "Ve cümle üç added hammâmdir. Evvelâ Beg hammâmi ve Haci Alî hammami ve Abîd Efendi hammâmi, hos-hevâ hammamlardir. Ve cümle iki added hân-1 tüccârandir. Ve cümle yüz bes added dükkânlardir, ammâ bezzâzistani yokdur. Lâkin cemî’i elbise-i fâhire ve metâ-ı nâdireler bulunur bazaar-1 hüsndür" dans Evliyâ Çelebi, Seyahatnamesi, viI Kitap, op. cit., p. 117.

29. Jacob Spon, op. cit., p. 253. Elles sont grosses et de très bon goût. Athénée au livre 4 et Hesychius appellent Colymbades, les olives apprêtées dans la saumure, dont les Anciens se 
servaient pour exciter l'appétit, parce qu'elles y nagent, car colymban signifie nager ; et ce nom leur est demeuré parce qu'on les prépare toujours de la même façon à l'époque où Jacob Spon se rend à Athènes.

30. Jacob Spon, op. cit., p. 191.

31. Jacob Spon, op. cit., p. 154.

32. “cennet ü cehennem ve a'râf u meydân-ı haşrde cem' olan cemî'i ecnâs-1 mahlûk-1 Hudâ'nın ehl-i cenneti, cennete melâ'ike-i Kerrûbiyânlar sürüp götürürken şâdımân ederek gider tasvîrlerin yazmış." dans Evliyâ Çelebi, Seyahatnamesi, viII Kitap, op. cit., p. 116.

33. Jacob Spon, op. cit., p. 158.

34. Ibid., p. 210.

35. Ibid., p. 219.

36. Ibid., p. 182.

37. Ibid., p. 201.

38. "cümle üç yüz added sağîr ü kebîr düyûr-i püt-gedelerdir kim cümle üç bin added bitrîkan-1 kıssîsân-1 ruhbânları vardır.” dans Evliyâ Çelebi, Seyahatnamesi, viII Kitap, op. cit., p. 118.

39. "cümle 3 mahalle-i müselmândir kim cümle bir yere vâki olmus(h) hânedânlardir. Ve cümle üç added câmi'lerdir. Mezkür iç kal'a câmi'iyle dörd mihrâbdir. Evvelâ (---) Beg câmi'i; kârgîr binâ kubâbli metîn ve ma'mûr câmi'i pürnûndur. Ve Haci Alî câmi'I ve Eski câmi. Bu üçü kârgîr kubbeli ve kiremit örtülü ma'bedgâhlardir. Bu sehirde aslâ kursum örtülü imâretler yokdur. Ve cümle yedi added mahalle mesâcidleri var. ve cümle bir added medrese-i âlimândir. Ve cümle üç added mekteb-i sibyândir. Ve cümle iki added tekye-i dervîsandir." dans Evliyâ Çelebi, Seyahatnamesi, VIII Kitap, op. cit., p. 117.

40. "Hüseyin Efendi tekyesi: Tarîk-i Halvetî'de ulu âsitâne-i sa'adetdir kim kapusu üzre târihi budur: Böyle dedi Mahdemî târîh ana, Ola makbûlü Hudâ'nın ol hümâm, Sene 1023." dans Evliyâ Çelebi, Seyahatnamesi, VIII Kitap, op. cit., p. 117.

41. “Bu şehr-i Atina'nın gün doğusu tarafında taht-ı Belkîs derler, Hazret-i Süleymân Nebî dîvlere fermân edüp yapmışlardır. Eğer bunun dahi evsâfını kemâ-kân olan eser-i binâ-yı amûd-ı gûnagûnları ve tâk-i Kisrâları ve kubâb-1 âlîleriyle ta'rîf ü tavsîf etsek bir kürrâs-1 kitâbet olur. Lâkin şimdiki hâlde Atina şehrinin namâzgâhıdır kim istiskâ du'âsına ve salât-1 ıydeyne cümle müslimîn pür-silâh olup çıkarlar, zîrâ bu şehirde müselmân kalmayup cümle kefereler kalır." dans Evliyâ Çelebi, Seyahatnamesi, VIII Kitap, op. cit., p. 118.

42. Jacob Spon, op. cit., p. 235.

43. “(Koçbaşı manastırı) buna dahi cemî'i kâfiristândan nezerâtlar gelir. Bin atlı gelse 'Hoşgeldiniz' deyü ta'zîm edüp ri'âyet ederler, ammâ Yahûdî varsa sabâh mürd olmuş bulunup kapkara yanmış bulunur, aceb hikmetdir." dans Evliyâ Çelebi, Seyahatnamesi, viII Kitap, op. cit., p. 120.

44. Jacob Spon, op. cit., p. 243.

45. Jacob Spon, op. cit., p. 130.

46. "Hemân ki ba'de'l-gurûb oldu, nice bin avretler fânûslarıyla mısra': "Ya'nî ki turâ mî-talebem hâne be hâne" mazmûnu üzre sabâha dek hânedânlarda ve hammâmlarda zevk u safâlar ederler" dans Evliyâ Çelebi, Seyahatnamesi, vıII Kitap, op. cit., p. 118.

47. Jacob Spon, op. cit., p. 238.

48. Il s'agirait du kameulafkion, d'origine probablement byzantine.

49. "Lâkin re'âyâ kefereleri başlarına Freng kalabağı gibi manlifke geyerler." dans Evliyâ Çelebi, Seyahatnamesi, VIII Kitap, op. cit., p. 118.

50. Jacob Spon, op. cit., p. 254.

51. Evliyâ Çelebi, Seyahatnamesi, viII Kitap, op. cit., p. 124.

52. Il signale dans sa curiosité médicale, un instrument pour la saignée « que les Grecs appellent Balestra ». 
53. "Ah benim bâğ-I Iremim Atina" dans Evliyâ Çelebi, Seyahatnamesi, VIII Kitap, op. cit., p. 113.

54. Les monuments de cette période ont beaucoup souffert de politiques nationalistes pratiquées par les États issus de l'Empire Ottoman dans les Balkans tout au long du XIX siècle et jusqu'à une période assez récente. Ces politiques pourraient être résumées par le terme de désottomanisation employé par Bernard Lory dans Le sort de l'héritage ottoman en Bulgarie : l'exemple des villes bulgares, Istanbul, Éditions Isis, 1985. Sur ce processus qui visait à un effacement systématique des traces de la période ottomane, voir Machiel Kiel, « Un héritage non désiré : le patrimoine architectural islamique ottoman dans l'Europe du Sud-Est, 1370-1912 ", Études Balkaniques, 2005, 12, p. 15-82 et Sylvie Gangloff, La perception de l'héritage ottoman dans les Balkans (actes des Journées d'études sur l'héritage ottoman dans les Balkans, Istanbul, 16-17 juin 2000), Paris, L'Harmattan, 2005. Pour un inventaire détaillé des monuments de la période ottomane en Grèce, voir Nusret Çam, Yunanistan'daki Türk eserleri (Les monuments turcs en Grèce), Ankara, TTK, XXI (8), 2000 Ismail Biçakçi, Yunanistan'da Türk mimari eserleri (Les œuvres architecturales turques en Grèce), Istanbul,

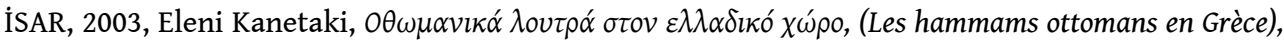
Athènes, TEE, 2004. Sur l'héritage ottoman de la ville d'Athènes, voir Mackenzie Molly, Turkish Athens: the forgotten centuries: 1456-1832, Reading, Ithaca Press, 1992, Travlos Ioannis, Athènes au fil

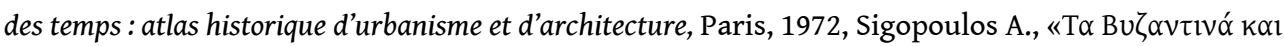

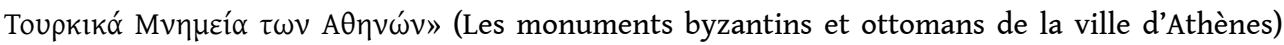

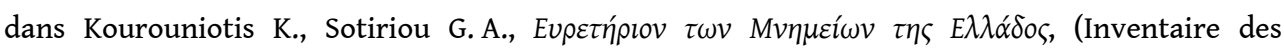
monuments en Grèce), AӨńva, 1929. Sur la prise de conscience de la valeur de cet héritage par les décideurs politiques, dans une politique de patrimonialisation et de développement d'approches historiques moins marquées par le nationalisme qui ont abouti à des travaux de restauration,

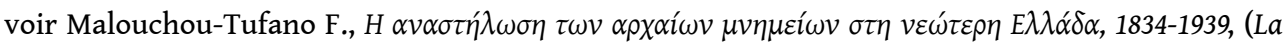
restauration de monuments de l'antiquité dans la Grèce contemporaine, 1834-1939), Xarkiolakis N. (dir.),

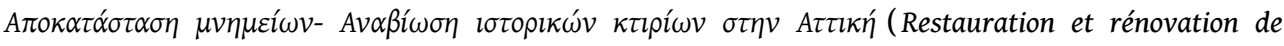
bâtiments historiques dans le département d'Attiki), 3, Athènes, 2006.

55. "ammâ bir âdem bu Atina şehrine varup tâ ilme'l-yakın hâsıl etmeyince bu Atina vilâyeti ve şehri zamân-1 kadîmde ne idiğin bilimez, zîrâ ta'rîf ü tavsîf ile olmaz.” dans Evliyâ Çelebi, Seyahatnamesi, VIII Kitap, op. cit., p. 117.

56. "Mısra' : şenîden key buved mânend-i dîde mazmûnunca iş itmek görmek gibi değildi (...)" dans Evliyâ Çelebi, Seyahatnamesi, VIII Kitap, op. cit., p. 117.

57. "Ve bu șehri gelüp görmeyen seyyâh- 1 âlem cihân-bînim demesin" dans Evliyâ Çelebi, Seyahatnamesi, VIII Kitap, op. cit., p. 117.

\section{RÉSUMÉS}

Au cours de la deuxième moitié du XvII ${ }^{\mathrm{e}}$ siècle, deux voyageurs, un Français, Jacob Spon et un Ottoman, Evliyâ Çelebi, se rendent dans la ville d'Athènes. Dans cet article, on esquisse à travers l'étude des mémoires de ces deux voyageurs, leurs perceptions de la ville, de son histoire, de sa topographie urbaine (lieux évoqués, monuments commentés), et de son organisation sociopolitique (institutions, relations intercommunautaires, mœurs et coutumes). L'objectif d'une telle analyse est de comprendre en quoi cette juxtaposition d'impressions et d'expressions, est révélatrice d'une représentation différenciée de l'altérité urbaine et humaine. De surcroît, ces récits, faute de documents officiels sur la ville d'Athènes de cette période, représentent des 
sources précieuses pour la reconstitution du paysage urbain et social dans la période ottomane. Leur caractère complémentaire, car en fonction de ses bagages culturels chaque voyageur ne retient pas et ne diffuse pas forcément les mêmes informations sur les réalités sensorielles et institutionnelles de la ville, révèle l'intérêt d'une approche comparatiste.

In the second half of the 17th century, two travellers, one French, Jacob Spon and one Ottoman, Evliyâ Çelebi, are visiting the city of Athens. This article aims at depicting, throughout the study of both travellers' memoirs, their perception of the city, regarding its history, its urban topography (places mentioned, monuments commented) and its socio-political organisation (institutions, relationships between the different communities, customs and habits). The purpose of such an analysis is to realise how the juxtaposition of these impressions and expressions reveals us a differentiated representation of urban and human otherness. Moreover, these narratives, for lack of official documents, provide us with precious information in order to piece together the city's urban and social landscape during its ottoman period. Their complementary character, as due to their different cultural backgrounds, each traveller does not necessarily retain or relate the same information upon the city's sensorial and institutional realities, demonstrates the interest of this comparative approach.

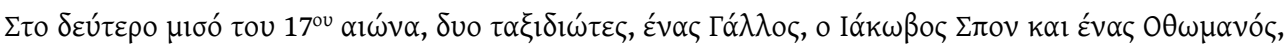

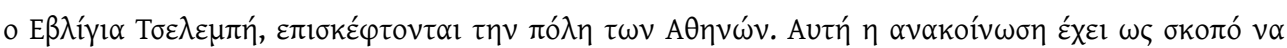

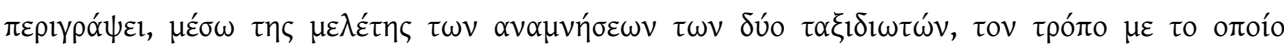

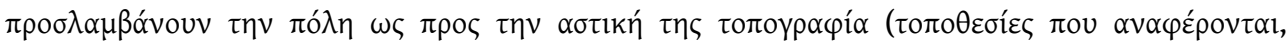

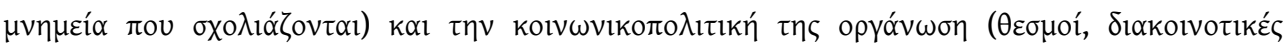

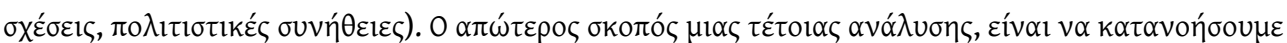

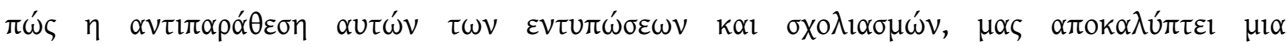

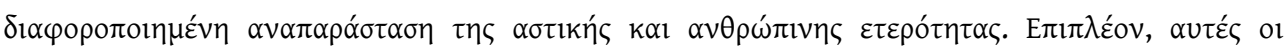

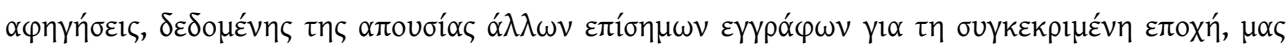

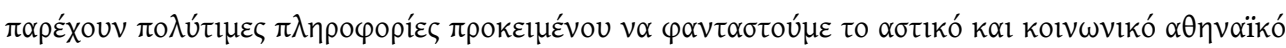

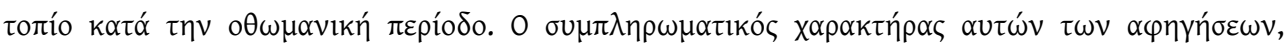

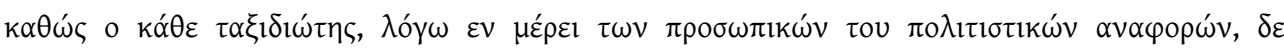

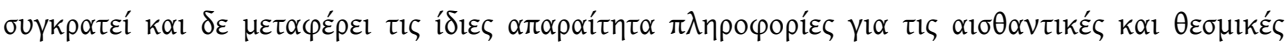

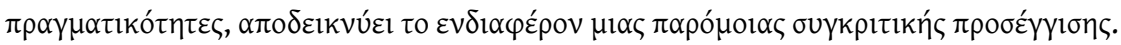




\section{INDEX}

motsclesmk ЕВЛИЈА ЧЕЛЕБИЈА, (1611-1682) СЕЈАХАТНАМЕ, СПОН ЈАКОВ(1647-1685), АТИНА ОТОМАНСКАТА, РЕПРЕЗЕНТАЦИИ, АТИНА, СЕДУМНАЕСЕТИОТ ВЕК, ОТОМАНСКАТА ИМПЕРИЈА, СЕДУЧИАЕСЕТИОТ ВЕК, ИСТОРИЈА, ИСТОРИА НА МЕНТАЛИТЕТ, ПАТЕПИСИ

Index géographique : Empire ottoman, Athènes motsclestr Evliyâ Çelebi (1611-1682), Seyahatnâme, Spon Jacob (1647-1685), Osmanli Atina, Tasvîr, Atina, smanlı İmparatorluğu, Onyedinci yüzyılda, arih, Zihniyetlerin Tarihi, Seyahtanameler

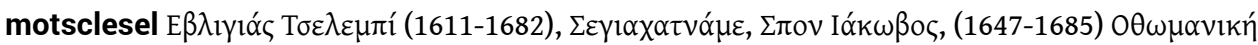

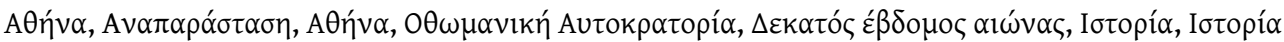

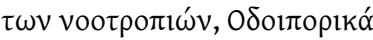

Mots-clés : Evliyâ Çelebi (1611-1682), Seyahatnâme, Seyahatnâme, récit de voyage, Spon Jacob (1647-1685), Spon Jacob (1647-1685), Athènes ottomane, représentations

Thèmes : Histoire, Histoire des mentalités

Keywords : Evliyâ Çelebi (1611-1682), Seyahatnâme, Spon Jacob (1647-1685), Ottoman Athens, representations, Athens, seventeenth century, History of mentalities, travelogues

Index chronologique : dix-septième siècle

\section{AUTEUR}

\section{NICOLAS PITSOS}

Doctorant

Inalco 